\title{
Allogeneic Hematopoietic Stem Cell Transplantation for Post-essential Thrombocythemia and Post-polycythemia Vera Myelofibrosis
}

\author{
Makoto Murata ${ }^{1,2}$, Ritsuro Suzuki ${ }^{3}$, Tetsuya Nishida ${ }^{1}$, Shuichi Shirane ${ }^{2,4}$, Yutaka Shimazu ${ }^{2,5}$, \\ Yosuke Minami ${ }^{2,6}$, Takehiko Mori ${ }^{7}$, Noriko Doki ${ }^{8}$, Yoshinobu Kanda ${ }^{9}$, Naoyuki Uchida ${ }^{10}$, \\ Masatsugu Tanaka ${ }^{11}$, Jun Ishikawa ${ }^{12}$, Kazuto Togitani ${ }^{13}$, Takahiro Fukuda ${ }^{14}$, Tatsuo Ichinohe ${ }^{15}$, \\ Yoshiko Atsuta ${ }^{16,17}$, Tokiko Nagamura-Inoue ${ }^{2,18}$ and Hitoshi Kiyoi ${ }^{1}$
}

\begin{abstract}
:
Objective Little information is available about the outcome of allogeneic hematopoietic stem cell transplantation (HSCT) for patients with secondary myelofibrosis from essential thrombocythemia (ET) and polycythemia vera (PV). A nationwide retrospective study of the outcome of HSCT for post-ET and post-PV myelofibrosis was conducted in Japan.

Patients and Methods Clinical data for patients with post-ET $(n=29)$ and post-PV $(n=9)$ myelofibrosis who had received first allogeneic HSCT were extracted from the Transplant Registry Unified Management Program, which is a registry of the outcomes of HSCT in Japan.

Results Five patients died without neutrophil recovery within 60 days after transplantation. The incidence of neutrophil recovery was significantly lower in umbilical cord blood (UCB) transplantation than in related donor transplantation $(40 \%$ vs. $92 \%, \mathrm{p}=0.010)$. The 1 -year non-relapse mortality for post-ET and post-PV myelofibrosis was $35 \%$ and $27 \%$, respectively $(\mathrm{p}=0.972)$. No patient or transplantation characteristics were associated with non-relapse mortality. The 4-year overall survival for post-ET and post-PV myelofibrosis was $46 \%$ and $65 \%$, respectively $(\mathrm{p}=0.362)$. A univariate analysis identified UCB transplantation (vs. related donor, $\mathrm{p}=0.017$ ) and $\geq 10$ times red blood cell transfusions before transplantation (vs. $<10$ times, $\mathrm{p}=0.037$ ) as predictive of a lower overall survival.

Conclusion Allogeneic HSCT provides a long-term survival for at least some patients with post-ET and post-PV myelofibrosis. Further studies with more patients are required to determine the best alternative donor.
\end{abstract}

Key words: myelofibrosis, essential thrombocythemia, polycythemia vera, hematopoietic stem cell transplantation, cord blood

(Intern Med 59: 1947-1956, 2020)

(DOI: 10.2169/internalmedicine.4375-19)

\footnotetext{
${ }^{1}$ Department of Hematology and Oncology, Nagoya University Graduate School of Medicine, Japan, ${ }^{2}$ Adult CML/MPN Working Group of the Japan Society for Hematopoietic Cell Transplantation, Japan, ${ }^{3}$ Department of Oncology and Hematology, Shimane University Hospital, Japan, ${ }^{4}$ Division of Hematology, Department of Internal Medicine, Juntendo University, Japan, ${ }^{5}$ Department of Hematology, Japanese Red Cross Wakayama Medical Center, Japan, ${ }^{6}$ Department of Hematology, National Cancer Center Hospital East, Japan, ${ }^{7}$ Division of Hematology, Department of Medicine, Keio University School of Medicine, Japan, ${ }^{8}$ Hematology Division, Tokyo Metropolitan Cancer and Infectious Diseases Center, Komagome Hospital, Japan, ${ }^{9}$ Division of Hematology, Jichi Medical University, Japan, ${ }^{10}$ Department of Hematology, Toranomon Hospital, Japan, ${ }^{11}$ Department of Hematology, Kanagawa Cancer Center, Japan, ${ }^{12}$ Department of Hematology, Osaka International Cancer Institute, Japan, ${ }^{13}$ Department of Hematology, Kochi Medical School, Japan, ${ }^{14}$ Hematopoietic Stem Cell Transplantation Division, National Cancer Center Hospital, Japan, ${ }^{15}$ Department of Hematology and Oncology, Research Institute for Radiation Biology and Medicine, Hiroshima University, Japan, ${ }^{16}$ Japanese Data Center for Hematopoietic Cell Transplantation, Japan, ${ }^{17}$ Department of Healthcare Administration, Nagoya University Graduate School of Medicine, Japan and ${ }^{18}$ Department of Cell Processing and Transfusion, The Institute of Medical Science, The University of Tokyo, Japan Received for publication December 23, 2019; Accepted for publication March 30, 2020

Correspondence to Dr. Makoto Murata, mmurata@med.nagoya-u.ac.jp
} 


\section{Introduction}

Essential thrombocythemia (ET) is a chronic myeloproliferative neoplasm characterized by sustained thrombocytosis in the peripheral blood and increased numbers of megakaryocytes in the bone marrow (1). ET has a long symptom-free period with the absence of life-threatening thromboembolic or hemorrhagic events. However, myelofibrosis occurs in about $10 \%$ of patients with a diagnosis of ET (2). Polycythemia vera (PV) is another chronic myeloproliferative neoplasm characterized by increased red blood cell production independent of the mechanisms that normally regulate erythropoiesis (3). The major symptoms of PV are related to hypertension or vascular abnormalities caused by the increased red blood cell mass. The incidence of myelofibrosis in patients with a diagnosis of PV is reported to be about $10-20 \%$ (2).

Despite the remarkable benefits of Janus kinase (JAK) inhibitors in terms of reducing splenomegaly and diseaserelated symptoms $(4,5)$, current drug therapy for post-ET and post-PV myelofibrosis is not curative and unlikely to prolong the survival (6). The only potentially curative therapy for secondary myelofibrosis is allogeneic hematopoietic stem cell transplantation (HSCT) (7). Nonetheless, there are few reports focusing on the outcomes of HSCT for patients with post-ET and post-PV myelofibrosis (8-10).

We herein report the results of a nationwide retrospective study to analyze the clinical outcomes of HSCT for post-ET and post-PV myelofibrosis in Japan.

\section{Materials and Methods}

\section{Patients}

Clinical data for patients with post-ET and post-PV myelofibrosis who had received first allogeneic HSCT were extracted from the Transplant Registry Unified Management Program (TRUMP), which is a registry of the outcomes of HSCT in Japan $(11,12)$. This program is sponsored by the Japan Society for Hematopoietic Cell Transplantation and the Japanese Data Center for Hematopoietic Cell Transplantation. More specifically, the clinical data for patients with "1" in the "no" column, "myelofibrosis" in the "mpd_subtype" column, and "secondary" in the "denovo_secondary" column were extracted from the TRUMP data. We then divided those patients into post-ET or post-PV myelofibrosis according to "ET" or "PV" in the "sec_malig_dx" column. Patients with other diseases, such as "AML", "MDS, " or "macroglobulinemia," in the "sec_malig_dx" column were excluded. Thus, neither primary myelofibrosis nor secondary myelofibrosis from diseases other than ET and PV was included in this study.

This study was approved by the Data Management Committee of the Japan Society for Hematopoietic Cell Transplantation and by the Ethics Committee of the Nagoya Uni- versity School of Medicine.

\section{Definitions}

The conditioning regimen intensity was classified as myeloablative conditioning or reduced-intensity conditioning based on the report by the Center for International Blood and Marrow Transplant Research (13). Neutrophil recovery was defined as an absolute neutrophil count of at least $0.5 \times$ $10^{9} / \mathrm{L}$ for 3 consecutive days. Engraftment failure was defined as no neutrophil recovery by day 60 . Acute graftversus-host disease (GVHD) and chronic GVHD were diagnosed and graded based on traditional criteria $(14,15)$.

\section{Endpoints}

The primary endpoint of this study was the overall survival (OS) after allogeneic HSCT in patients with post-ET and post-PV myelofibrosis. Other endpoints included neutrophil recovery, acute and chronic GVHD, relapse rate, nonrelapse mortality (NRM), causes of death, and the impacts of patient and transplant characteristics on the transplant outcome.

\section{Statistical analyses}

The probabilities of neutrophil recovery, the acute and chronic GVHD rate, the relapse rate, and NRM stratified by primary disease and donor sources were estimated based on cumulative incidence curves (16). A competing risk regression analysis was used to identify factors associated with NRM. The probabilities of the OS stratified by primary disease and donor sources were estimated according to the Kaplan-Meier method (17). The groups were compared using the log-rank test. Cox's proportional hazards model was used to identify factors associated with the OS (18). All tests were two-sided, and $p<0.05$ was considered significant. The data were analyzed by the STATA version 12 statistical software program (StataCorp, College Station, USA).

\section{Results}

\section{Patient and transplantation characteristics}

Twenty-nine patients with post-ET myelofibrosis and nine with post-PV myelofibrosis met the inclusion criteria. Transplantation was performed between 2005 and 2017. The median age at transplantation was 55 years old (range, 40-68 years old). Patient and transplantation characteristics stratified by primary disease are summarized in Table 1 . Of the 13 related donor transplantation cases, $2(15 \%)$ were performed with bone marrow (BM) from a serological HLA-A, $-\mathrm{B}$, and -DR 6/6 matched donor, and $11(85 \%)$ were performed with peripheral blood stem cells (PB) from a serological HLA-A, -B, and -DR 6/6 matched donor. Of the 19 unrelated donor transplantation cases, 18 (95\%) were performed with BM from HLA-A, -B, -C, and -DRB1 alleles $8 / 8$ matched $(n=13), 7 / 8$ matched $(n=3), 6 / 8$ matched $(n=1)$, or $4 / 8$ matched $(n=1)$ donors, and $1(5 \%)$ was performed 
Table 1. Patient and Transplantation Characteristics Stratified by Primary Disease $(\mathbf{n}=38)$.

\begin{tabular}{|c|c|c|c|}
\hline & Post-ET & Post-PV & $\mathrm{p}$ value \\
\hline Number of patients & 29 & 9 & \\
\hline Median age (range), y & $53(40-68)$ & $57(45-61)$ & \\
\hline \multicolumn{4}{|l|}{ Age at transplant, $\mathrm{n}(\%)$} \\
\hline $40-54$ y & $16(55)$ & $3(33)$ & 0.45 \\
\hline $55-68$ y & $13(45)$ & $6(67)$ & \\
\hline \multicolumn{4}{|l|}{ Sex, n $(\%)$} \\
\hline Male & $17(59)$ & $7(78)$ & 0.44 \\
\hline Female & $12(41)$ & $2(22)$ & \\
\hline \multicolumn{4}{|c|}{ Performance status at transplant, $\mathrm{n}(\%)$} \\
\hline 0 or 1 & $25(86)$ & $9(100)$ & 0.55 \\
\hline$\geq 2$ & $4(14)$ & $0(0)$ & \\
\hline \multicolumn{4}{|c|}{ Time from diagnosis to transplant, $\mathrm{n}(\%)$} \\
\hline$<3 \mathrm{y}$ & $16(55)$ & $3(33)$ & 0.45 \\
\hline$\geq 3 \mathrm{y}$ & $13(45)$ & $6(67)$ & \\
\hline \multicolumn{4}{|c|}{ Frequency of RBC transfusion before transplant, $\mathrm{n}(\%)$} \\
\hline$<10$ times & $9(31)$ & $4(45)$ & 0.11 \\
\hline$\geq 10$ times & $17(59)$ & $2(22)$ & \\
\hline Unknown & $3(10)$ & $3(33)$ & \\
\hline \multicolumn{4}{|c|}{ Frequency of PLT transfusion before transplant, $\mathrm{n}(\%)$} \\
\hline$<10$ times & $19(66)$ & $6(67)$ & 0.52 \\
\hline$\geq 10$ times & $7(24)$ & $1(11)$ & \\
\hline Unknown & $3(10)$ & $2(22)$ & \\
\hline \multicolumn{4}{|l|}{ DIPSS at transplant, $\mathrm{n}(\%)$} \\
\hline Low or intermediate-1 & $2(7)$ & $0(0)$ & 0.60 \\
\hline Intermediate- 2 or high & $9(31)$ & $4(44)$ & \\
\hline Unknown & $18(62)$ & $5(56)$ & \\
\hline \multicolumn{4}{|l|}{ Splenomegaly at transplant, $\mathrm{n}(\%)$} \\
\hline No & $1(4)$ & $0(0)$ & 0.76 \\
\hline Yes & $10(34)$ & $4(44)$ & \\
\hline Unknown & $18(62)$ & $5(56)$ & \\
\hline \multicolumn{4}{|c|}{ Use of JAK inhibitor before transplant, n (\%) } \\
\hline No & $4(14)$ & $1(11)$ & 0.83 \\
\hline Yes & $4(14)$ & $2(22)$ & \\
\hline Unknown & $21(72)$ & $6(67)$ & \\
\hline \multicolumn{4}{|l|}{ Donor, n (\%) } \\
\hline Related donor & $10(34)$ & $3(33)$ & 0.94 \\
\hline Unrelated donor & $14(49)$ & $5(56)$ & \\
\hline Umbilical cord blood & $4(14)$ & $1(11)$ & \\
\hline HLA-haplo donor & $1(3)$ & $0(0)$ & \\
\hline \multicolumn{4}{|l|}{ Conditioning regimen, $\mathrm{n}(\%)$} \\
\hline Myeloablative conditioning & $17(59)$ & $4(44)$ & 0.70 \\
\hline Reduced-intensity conditioning & $12(41)$ & $5(56)$ & \\
\hline \multicolumn{4}{|l|}{ Prophylaxis for GVHD, n (\%) } \\
\hline Tacrolimus+methotrexate & $14(48)$ & $6(67)$ & 0.31 \\
\hline Cyclosporine+methotrexate & $9(31)$ & $3(33)$ & \\
\hline Other* & $6(21)$ & $0(0)$ & \\
\hline \multicolumn{4}{|c|}{ Use of antithymocyte globulin at transplant, n (\%) } \\
\hline No & $26(90)$ & $7(78)$ & 0.57 \\
\hline Yes & $3(10)$ & $2(22)$ & \\
\hline
\end{tabular}

*Other includes tacrolimus alone $(n=1)$, tacrolimus+mycophenolate mofetil $(n=3)$, cyclosporine alone $(\mathrm{n}=1)$, and cyclosporine+mycophenolate mofetil+post-transplant cyclophosphamide $(\mathrm{n}=1)$.

ET: essential thrombocythemia, PV: polycythemia vera, RBC: red blood cell, PLT: platelet, DIPSS: Dynamic International Prognostic Scoring System, JAK: Janus kinase, GVHD: graft-versus-host disease 
with PB from an HLA-A, -B, -C, and -DRB1 alleles 7/8 matched donor. All five unrelated umbilical cord blood (UCB) transplantation cases were performed with a single unit of UCB from a serological HLA-A, -B, and -DR 4/6 matched donor. UCB contained a median of 2.67 (range, $2.01-3.81) \times 10^{7} / \mathrm{kg}$ cryopreserved total nucleated cells and a median of 0.78 (range, $0.55-0.95$ ) $\times 10^{5} / \mathrm{kg}$ cryopreserved CD 34-positive cells. One patient with post-ET myelofibrosis received PB transplantation from an HLA one haplotypemismatched related donor (HLA-haplo donor) with posttransplant cyclophosphamide. There were no significant differences in the patient or transplantation characteristics between post-EV and post-PV myelofibrosis. The median follow-up duration for living patients was 4.3 (0.3-9.7) years.

The patient and transplantation characteristics stratified by the donor are summarized in Table 2. The patient's sex, splenomegaly at transplant, and prophylaxis for GVHD were significantly different between donors, although the number of patients in each donor group was small. In UCB transplantation, 3 patients received myeloablative conditioning (cytarabine $12 \mathrm{~g} / \mathrm{m}^{2}+$ cyclophosphamide $120 \mathrm{mg} / \mathrm{kg}+$ total body irradiation $12 \mathrm{~Gy}$, fludarabine $180 \mathrm{mg} / \mathrm{m}^{2}+$ intravenous busulfan $12.8 \mathrm{mg} / \mathrm{kg}$ +total body irradiation $2 \mathrm{~Gy}$, or fludarabine $180 \mathrm{mg} / \mathrm{m}^{2}+$ intravenous busulfan $12.8 \mathrm{mg} / \mathrm{kg}+$ melphalan $80 \mathrm{mg} / \mathrm{m}^{2}$ ), and 2 received reduced-intensity conditioning (fludarabine $125 \mathrm{mg} / \mathrm{m}^{2}+$ melphalan $140 \mathrm{mg} / \mathrm{m}^{2}+$ total body irradiation 4 Gy or fludarabine $180 \mathrm{mg} / \mathrm{m}^{2}+$ melphalan 80 $\mathrm{mg} / \mathrm{m}^{2}+$ total body irradiation $4 \mathrm{~Gy}$ ). One patient received tacrolimus + methotrexate, two received cyclosporine + methotrexate, and two received tacrolimus+mycophenolate mofetil as prophylaxis for GVHD.

\section{Engraftment}

Five patients $(13 \%)$ died without engraftment within 60 days after transplantation, due to bleeding $(n=2)$ on days 7 and 48 , bacterial infection $(n=1)$ on day 15 , acute respiratory distress syndrome $(n=1)$ on day 15 , and multiple organ failure $(n=1)$ on day 12 . The incidences of neutrophil recovery on day 60 in patients with post-ET and post-PV myelofibrosis were $83 \%$ [95\% confidence interval (CI), 6392\%] and $89 \%$ (43-98\%), respectively (Fig. 1a). There was no significant difference in the incidence of neutrophil recovery between post-ET and post-PV myelofibrosis ( $\mathrm{p}=$ $0.591)$. The median days to neutrophil recovery in patients with post-ET and post-PV myelofibrosis were 21 and 20, respectively.

The incidences of neutrophil recovery on day 60 after related donor, unrelated donor, and UCB transplantation were $92 \%(57-99 \%), 89 \%(64-97 \%)$, and $40 \%$ (5-75\%), respectively (Fig. 1b). Compared with related donor transplantation, the incidence of neutrophil recovery after unrelated donor transplantation was not significantly different $(\mathrm{p}=0.107)$, whereas that after UCB transplantation was significantly lower $(\mathrm{p}=0.010)$. The median days to neutrophil recovery after related donor, unrelated donor, and UCB transplantation were 17, 24, and 29, respectively.

A patient receiving HLA-haplo donor transplantation achieved neutrophil recovery on day 20. Use of JAK inhibitor before transplantation was not associated with the incidence of neutrophil recovery.

\section{GVHD}

The incidences of grade II-IV acute GVHD on day 100 in patients with post-ET and post-PV myelofibrosis were $10 \%$ (95\% CI, 3-24\%) and 11\% (1-39\%), respectively ( $\mathrm{p}=0.910)$. The incidences of grade II-IV acute GVHD on day 100 after related donor, unrelated donor, and UCB transplantation were $15 \%(2-39 \%), 5 \%(0-21 \%)$, and $20 \%$ (1-58\%), respectively (unrelated donor vs. related donor, $\mathrm{p}=0.385$; UCB vs. related donor, $\mathrm{p}=0.811$ ). The incidences of chronic GVHD at 1 year in patients with post-ET and post-PV myelofibrosis were $18 \%(7-34 \%)$ and $13 \%(1-42 \%)$, respectively $(\mathrm{p}=$ 0.720 ). The incidences of chronic GVHD at 1 year after related donor, unrelated donor, and UCB transplantation were $23 \%(6-47 \%), 6 \%(0-24 \%)$, and 20\% (1-58\%), respectively (unrelated donor vs. related donor, $\mathrm{p}=0.179$; UCB vs. related donor, $\mathrm{p}=0.832$ ). A patient receiving HLA-haplo donor transplantation developed neither acute GVHD nor chronic GVHD. Use of JAK inhibitor before transplantation was not associated with the incidences of acute or chronic GVHD.

\section{Relapse}

Fourteen patients relapsed after transplantation. Five cases were diagnosed as hematological relapse, two as cytogenetic relapse, and four as molecular relapse; the diagnostic methods were unknown in three patients. The relapse rates at 1 year in patients with post-ET and post-PV myelofibrosis were $42 \%$ (95\% CI, 24-59\%) and $11 \%$ (1-39\%), respectively, and those at 4 years were $47 \%(27-64 \%)$ and $11 \%$ $(1-39 \%)$, respectively $(\mathrm{p}=0.145)$. The relapse rates at 1 year after related donor, unrelated donor, and UCB transplantation were $31 \%(9-55 \%), 32 \%(13-53 \%)$, and $40 \%(5-75 \%)$, respectively, and those at 4 years after related donor and unrelated donor transplantation were $31 \%(9-55 \%)$ and $42 \%$ (18-64\%), respectively (unrelated donor vs. related donor, $\mathrm{p}$ $=0.716$; UCB vs. related donor, $\mathrm{p}=0.676$ ). A patient receiving HLA-haplo donor transplantation relapsed on day 150. Use of JAK inhibitor before transplantation was not associated with the relapse rate.

\section{NRM}

The NRM rates at 1 year in patients with post-ET and post-PV myelofibrosis were 35\% (95\% CI, 14-57\%) and $27 \%(4-59 \%)$, respectively, and those at 4 years were $35 \%$ (14-57\%) and 27\% (4-59\%), respectively (Fig. 2a). The $\mathrm{NRM}$ rates at 1 year after related donor, unrelated donor, and UCB transplantation were $11 \%$ (1-39\%), 42\% (15$67 \%$ ), and $50 \%(6-84 \%)$, respectively, and those at 4 years after related donor and unrelated donor transplantation were $11 \%(1-39 \%)$ and $42 \%$ (15-67\%), respectively (Fig. 2b). To identify risk factors for NRM, a univariate analysis was per- 
Table 2. Patient and Transplantation Characteristics Stratified by Donor $(n=38)$.

\begin{tabular}{|c|c|c|c|c|c|}
\hline & Related & Unrelated & UCB & HLA-haplo & $\mathrm{p}$ value \\
\hline Number of patients & 13 & 19 & 5 & 1 & \\
\hline Median age (range), y & $53(40-59)$ & $53(40-68)$ & $62(57-68)$ & 49 & \\
\hline \multicolumn{6}{|l|}{ Age at transplant, $\mathrm{n}(\%)$} \\
\hline $40-54$ y & $7(54)$ & $11(58)$ & $0(0)$ & $1(100)$ & 0.09 \\
\hline $55-68$ y & $6(46)$ & $8(42)$ & $5(100)$ & $0(0)$ & \\
\hline \multicolumn{6}{|l|}{ Sex, n $(\%)$} \\
\hline Male & $4(31)$ & $15(79)$ & $4(80)$ & $1(100)$ & 0.03 \\
\hline Female & $9(69)$ & $4(21)$ & $1(20)$ & $0(0)$ & \\
\hline \multicolumn{6}{|l|}{ Primary disease, $\mathrm{n}(\%)$} \\
\hline ET & $10(77)$ & $14(74)$ & $4(80)$ & $1(100)$ & 0.94 \\
\hline PV & $3(23)$ & $5(26)$ & $1(20)$ & $0(0)$ & \\
\hline \multicolumn{6}{|c|}{ Performance status at transplant, $\mathrm{n}(\%)$} \\
\hline 0 or 1 & $11(85)$ & $17(89)$ & $5(100)$ & $1(100)$ & 0.79 \\
\hline$\geq 2$ & $2(15)$ & $2(11)$ & $0(0)$ & $0(0)$ & \\
\hline \multicolumn{6}{|c|}{ Time from diagnosis to transplant, $\mathrm{n}(\%)$} \\
\hline$<3$ y & $9(69)$ & $7(37)$ & $2(40)$ & $1(100)$ & 0.22 \\
\hline$\geq 3 \mathrm{y}$ & $4(31)$ & $12(63)$ & $3(60)$ & $0(100)$ & \\
\hline \multicolumn{6}{|c|}{ Frequency of RBC transfusion before transplant, $\mathrm{n}(\%)$} \\
\hline$<10$ times & $5(38)$ & $7(37)$ & $0(0)$ & $1(100)$ & 0.17 \\
\hline$\geq 10$ times & $8(62)$ & $7(37)$ & $4(80)$ & $0(0)$ & \\
\hline Unknown & $0(0)$ & $5(26)$ & $1(20)$ & $0(0)$ & \\
\hline \multicolumn{6}{|c|}{ Frequency of PLT transfusion before transplant, n (\%) } \\
\hline$<10$ times & $10(77)$ & $12(63)$ & $2(40)$ & $1(100)$ & 0.52 \\
\hline$\geq 10$ times & $3(24)$ & $3(16)$ & $2(40)$ & $0(0)$ & \\
\hline Unknown & $0(0)$ & $4(21)$ & $1(20)$ & $0(0)$ & \\
\hline \multicolumn{6}{|l|}{ DIPSS at transplant, $\mathrm{n}(\%)$} \\
\hline Low or intermediate-1 & $1(8)$ & $1(5)$ & $0(0)$ & $0(0)$ & 0.64 \\
\hline Intermediate- 2 or high & $4(31)$ & $5(26)$ & $3(60)$ & $1(100)$ & \\
\hline Unknown & $8(61)$ & $13(69)$ & $2(40)$ & $0(0)$ & \\
\hline \multicolumn{6}{|l|}{ Splenomegaly at transplant, $\mathrm{n}(\%)$} \\
\hline No & $0(0)$ & $0(0)$ & $0(0)$ & $1(100)$ & $<0.01$ \\
\hline Yes & $5(38)$ & $6(32)$ & $3(60)$ & $0(0)$ & \\
\hline Unknown & $8(62)$ & $13(68)$ & $2(40)$ & $0(0)$ & \\
\hline \multicolumn{6}{|c|}{ Use of JAK inhibitor before transplant, $\mathrm{n}(\%)$} \\
\hline No & $1(8)$ & $3(16)$ & $1(20)$ & $0(0)$ & 0.17 \\
\hline Yes & $4(31)$ & $0(0)$ & $2(40)$ & $0(0)$ & \\
\hline Unknown & $8(61)$ & $16(84)$ & $2(40)$ & $1(100)$ & \\
\hline \multicolumn{6}{|l|}{ Conditioning regimen, $\mathrm{n}(\%)$} \\
\hline Myeloablative conditioning & $10(77)$ & $7(37)$ & $3(60)$ & $1(100)$ & 0.12 \\
\hline Reduced-intensity conditioning & $3(23)$ & $12(63)$ & $2(40)$ & $0(0)$ & \\
\hline \multicolumn{6}{|l|}{ Prophylaxis for GVHD, n (\%) } \\
\hline Tacrolimus+methotrexate & $2(15)$ & $17(90)$ & $1(20)$ & $0(0)$ & $<0.01$ \\
\hline Cyclosporine+methotrexate & $9(70)$ & $1(5)$ & $2(40)$ & $0(0)$ & \\
\hline Other* & $2(15)$ & $1(5)$ & $2(40)$ & $1(100)$ & \\
\hline \multicolumn{6}{|c|}{ Use of antithymocyte globulin at transplant, $\mathrm{n}(\%)$} \\
\hline No & $11(85)$ & $16(84)$ & $5(100)$ & $1(100)$ & 0.78 \\
\hline Yes & $2(15)$ & $3(16)$ & $0(0)$ & $0(0)$ & \\
\hline
\end{tabular}

formed for all categorical variables listed in Table 1. No patransplantation was not associated with the NRM rate. tient or transplantation characteristics were significantly associated with NRM (Table 3). Use of JAK inhibitor before 
(a)

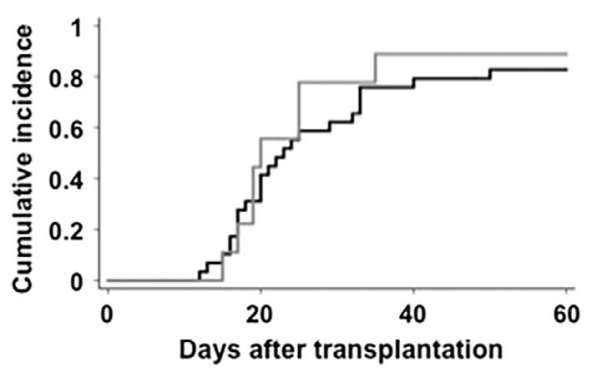

(b)

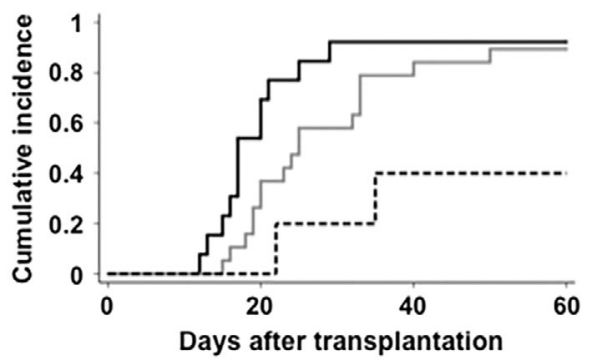

Figure 1. Neutrophil recovery after transplantation. (a) $\mathrm{Cu}$ mulative incidences of neutrophil recovery after transplantation in patients with post-ET (black line) and post-PV (grey line) myelofibrosis are shown. (b) Cumulative incidences of neutrophil recovery after related donor (black and solid line), unrelated donor (grey and solid line), and UCB (black and dash line) transplantation are shown. ET: essential thrombocythemia, PV: polycythemia vera, UCB: umbilical cord blood

\section{OS}

The OS rates at 1 year in patients with post-ET and postPV myelofibrosis were 51\% (95\% CI, 31-67\%) and $65 \%$ (25-87\%), respectively, and those at 4 years were $46 \%$ (27$64 \%$ ) and $65 \%(25-87 \%)$, respectively (log-rank, $\mathrm{p}=0.362$ ) (Fig. 3a). The OS rates at 1 year after related donor, unrelated donor, and UCB transplantation were $69 \%$ (37-87\%), $50 \%$ (26-70\%), and $20 \%$ (1-58\%), respectively, and those at 4 years after related donor and unrelated donor transplantation were $69 \%(37-87 \%)$ and $50 \%(26-70 \%)$, respectively (log-rank, p=0.0259) (Fig. 3b). To identify risk factors for the OS, a univariate analysis was performed for all categorical variables listed in Table 1. UCB transplantation and a higher frequency of RBC transfusion before transplantation were significantly associated with a lower OS (Table 3). Other patient and transplantation characteristics were not significantly associated with the OS. Use of JAK inhibitor before transplantation was not associated with the OS rate.

\section{Causes of death}

In addition to five patients who died without engraftment, as previously described, 13 patients died of hepatic venoocclusive disease $(n=1)$; GVHD $(n=1)$; thrombotic microangiopathy $(n=1)$; bacterial $(n=2)$, fungal $(n=1)$, and viral $(n=$ 1) infections; interstitial pneumonia $(n=1)$; acute respiratory distress syndrome $(n=1)$; multiple organ failure $(n=1)$; and (a)

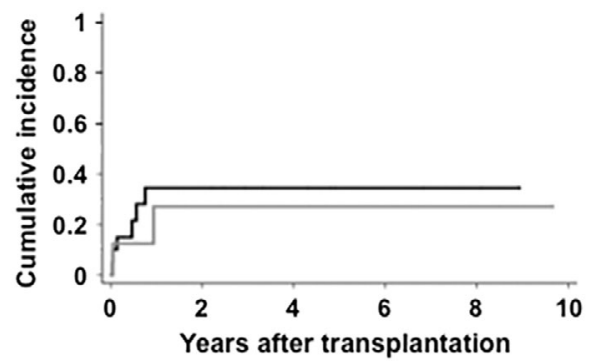

(b)

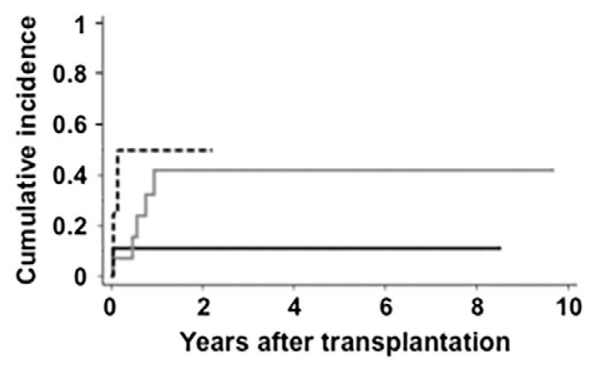

Figure 2. NRM after transplantation. (a) Cumulative incidences of NRM after transplantation in patients with post-ET (black line) and post-PV (grey line) myelofibrosis are shown. (b) Cumulative incidences of NRM after related donor (black and solid line), unrelated donor (grey and solid line), and UCB (black and dash line) transplantation are shown. NRM: nonrelapse mortality, ET: essential thrombocythemia, PV: polycythemia vera, UCB: umbilical cord blood

relapse $(n=3)$.

\section{Discussion}

The present study demonstrated no significant differences in the incidence of neutrophil recovery, incidences of acute and chronic GVHD, relapse rate, NRM, and the OS between post-ET and post-PV myelofibrosis. Little information has been available comparing transplant outcomes between postET and post-PV myelofibrosis. Lussana et al. reported no marked differences in the 3-year NRM and OS rates between post-ET and post-PV myelofibrosis (10). In contrast, Ballen et al. reported a significantly higher 5-year NRM for post-ET myelofibrosis than for post-PV myelofibrosis (9). Thus, whether or not the transplant outcomes for post-ET and post-PV myelofibrosis are equivalent remains controversial.

The OS was significantly lower in UCB transplantation than in related donor transplantation. NRM was not significantly different between UCB and related donor transplantation. However, the incidence of neutrophil recovery was significantly lower in UCB transplantation than in related donor transplantation. These results suggest that efforts to increase the incidence of neutrophil recovery may help improve the OS in UCB transplantation for secondary myelofibrosis. Nonetheless, the present cohort included only five patients undergoing UCB transplantation. Robin et al. evaluated 35 UCB transplantation cases for myelofibrosis, includ- 
Table 3. Univariate Analysis of Non-relapse Mortality and Overall Survival.

\begin{tabular}{|c|c|c|}
\hline & HR $(95 \%$ CI $)$ & $\mathrm{p}$ value \\
\hline \multicolumn{3}{|l|}{ Non-relapse mortality } \\
\hline \multicolumn{3}{|l|}{ Primary disease } \\
\hline ET $(n=29)$ & 1 & \\
\hline $\mathrm{PV}(\mathrm{n}=9)$ & $1.03(0.22-4.89)$ & 0.972 \\
\hline \multicolumn{3}{|l|}{ Donor } \\
\hline Related donor (n=13) & 1 & \\
\hline Unrelated donor $(\mathrm{n}=19)$ & $3.62(0.39-33.93)$ & 0.259 \\
\hline Umbilical cord blood $(n=5)$ & $6.51(0.51-83.24)$ & 0.150 \\
\hline \multicolumn{3}{|l|}{ Overall survival } \\
\hline \multicolumn{3}{|l|}{ Primary disease } \\
\hline ET $(n=29)$ & 1 & \\
\hline $\mathrm{PV}(\mathrm{n}=9)$ & $0.57(0.16-1.96)$ & 0.370 \\
\hline \multicolumn{3}{|l|}{ Donor } \\
\hline Related donor $(\mathrm{n}=13)$ & 1 & \\
\hline Unrelated donor $(\mathrm{n}=19)$ & $1.62(0.50-5.26)$ & 0.423 \\
\hline Umbilical cord blood $(\mathrm{n}=5)$ & $5.63(1.36-23.29)$ & 0.017 \\
\hline \multicolumn{3}{|c|}{ Frequency of RBC transfusion before transplantation } \\
\hline$<10$ times $(\mathrm{n}=13)$ & 1 & \\
\hline$\geq 10$ times $(\mathrm{n}=19)$ & $3.93(1.08-14.22)$ & 0.037 \\
\hline
\end{tabular}

The results of univariate analysis for primary disease, donor, and significant factors are shown selectively.

HR: hazard ratio, CI: confidence interval, ET: essential thrombocythemia, PV: polycythemia vera, RBC: red blood cell

(a)

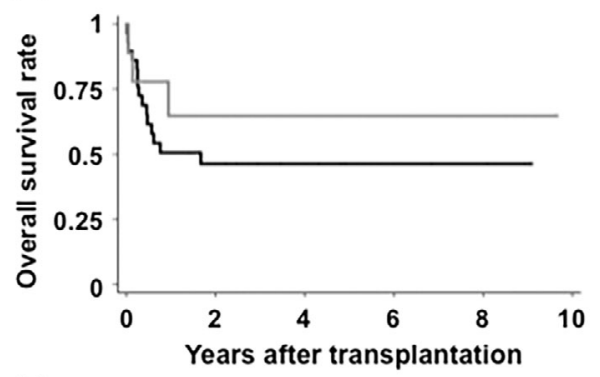

(b)

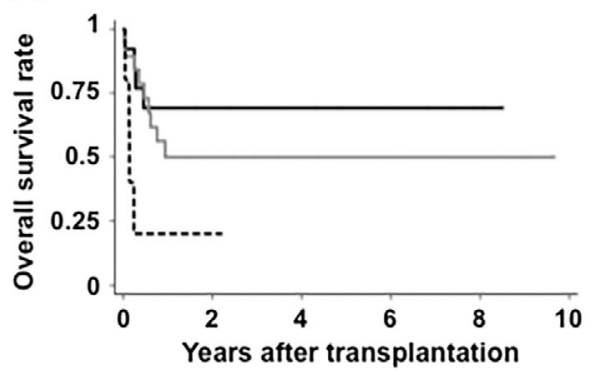

Figure 3. The OS rate after transplantation. (a) The OS rates after transplantation in patients with post-ET (black line) and post-PV (grey line) myelofibrosis are shown. (b) The OS rates after related donor (black and solid line), unrelated donor (grey and solid line), and UCB (black and dash line) transplantation are shown. OS: overall survival, ET: essential thrombocythemia, PV: polycythemia vera, UCB: umbilical cord blood

ing 15 secondary myelofibrosis from ET, PV, or acute myeloid leukemia, and reported a 2-year OS of $44 \%$ (19).
Takagi et al. evaluated $14 \mathrm{UCB}$ transplantation cases for myelofibrosis, including 11 secondary myelofibrosis from acute myeloid leukemia, and reported a 4-year OS of $29 \%$ (20). The recent nationwide retrospective study of HSCT for Japanese patients with primary myelofibrosis reported that the 1- and 4-year OS rates in UCB transplantation $(n=29)$ were $48 \%$ and $27 \%$, respectively, and that NRM was significantly higher in UCB transplantation than in HLA-matched related donor BM transplantation (21). Further analyses with more patients are required to evaluate the differences in the transplant outcomes for secondary myelofibrosis between UCB transplantation and related or unrelated donor transplantation.

Frequent ( $\geq 10$ times) RBC transfusion before transplantation was identified as a risk factor for the OS. This is compatible with previous analyses of HSCT for primary myelofibrosis (21-23). The Japanese national registry includes the Dynamic International Prognostic Scoring System (DIPSS) score, but not the DIPSS Plus score, which takes into account the information on RBC transfusion dependency and thrombocytopenia (24). Therefore, if the DIPSS Plus score had been available, it might have been identified as a predictor of the transplant outcome.

The median ages at transplantation for post-ET and postPV myelofibrosis were 53 and 57 years old, respectively. These ages are younger than the median ages of the general patient cohorts of ET (approximately 55 years old), PV (approximately 64 years old), and primary myelofibrosis (approximately 65 years old) $(2,25)$. A younger patient age is reported to be associated with a higher OS in HSCT for 
Table 4. Comparison of Transplant Outcomes of Japanese Patients with Primary and Secondary Myelofibrosis.

\begin{tabular}{lcc}
\hline & PMF $(21)$ & SMF (present study) \\
\hline HLA-matched related donor PB transplantation & & \\
Number of patients & 48 & $13 *$ \\
Neutrophil recovery on day 60 & $94(82-98) * * \%$ & $92(57-99) \%$ \\
Median time to neutrophil recovery & $16 \mathrm{~d}$ & $17 \mathrm{~d}$ \\
Grade II-IV acute GVHD on day 100 & $27(16-40) \%$ & $15(2-39) \%$ \\
Chronic GVHD at 1 y & $38(25-52) \%$ & $23(6-47) \%$ \\
Relapse at 1 y & $17(8-29) \%$ & $31(9-55) \%$ \\
Relapse at 4 y & $17(8-29) \%$ & $31(9-55) \%$ \\
NRM at 1 y & $36(22-50) \%$ & $11(1-39) \%$ \\
NRM at 4 y & $41(26-56) \%$ & $11(1-39) \%$ \\
OS at 1 y & $58(43-71) \%$ & $69(37-87) \%$ \\
OS at 4 y & $52(37-65) \%$ & $69(37-87) \%$ \\
Unrelated donor BM transplantation & & \\
Number of patients & 91 & $19 * * *$ \\
Neutrophil recovery on day 60 & $86(77-92) \%$ & $89(64-97) \%$ \\
Median time to neutrophil recovery & $21 \mathrm{~d}$ & $24 \mathrm{~d}$ \\
Grade II-IV acute GVHD on day 100 & $27(18-36) \%$ & $5(0-21) \%$ \\
Chronic GVHD at 1 y & $31(22-41) \%$ & $6(0-24) \%$ \\
Relapse at 1 y & $11(6-19) \%$ & $32(13-53) \%$ \\
Relapse at 4 y & $13(7-21) \%$ & $42(18-64) \%$ \\
NRM at 1 y & $30(21-41) \%$ & $42(15-67) \%$ \\
NRM at 4 y & $48(36-59) \%$ & $42(15-67) \%$ \\
OS at 1 y & $61(50-70) \%$ & $50(26-70) \%$ \\
OS at 4 y & $46(35-57) \%$ & $50(26-70) \%$ \\
UCB transplantation & 29 & \\
Number of patients & $79(58-90) \%$ & $40(5-75) \%$ \\
Neutrophil recovery on day 60 & $25 \mathrm{~d}$ & $29 \mathrm{~d}$ \\
Median time to neutrophil recovery & $31(16-48) \%$ & $20(1-58) \%$ \\
Grade II-IV acute GVHD on day 100 & $15(5-31) \%$ & $20(1-58) \%$ \\
Chronic GVHD at 1 y & $14(4-30) \%$ & $40(5-75) \%$ \\
Relapse at 1 y & $41(22-60) \%$ & $50(6-84) \%$ \\
NRM at 1 y & $48(29-64) \%$ & $20(1-58) \%$ \\
OS at 1 y & & 5 \\
\hline
\end{tabular}

*Two patients with BM transplantation from HLA-matched related donor are included.

$* * 95 \%$ confidence interval is in parentheses.

***One patient with PB transplantation from unrelated donor is included.

PMF: primary myelofibrosis, SMF: secondary myelofibrosis, PB: peripheral blood stem cell, GVHD: graft-versus-host disease, NRM: non-relapse mortality, OS: overall survival, BM: bone marrow, UCB: umbilical cord blood

myelofibrosis $(21,26,27)$. Thus, it should be noted that the efficacy of HSCT for secondary myelofibrosis might have been accentuated in this study.

A comparison of transplant outcomes of Japanese patients with primary (21) and secondary (present study) myelofibrosis is summarized in Table 4. HLA-matched related donor PB transplantation for secondary myelofibrosis showed a lower NRM and higher OS than that for primary myelofibrosis; however, this was not replicated in unrelated donor BM and UCB transplantation. Some studies have reported no significant differences in the NRM or OS between primary and secondary myelofibrosis (28-31). However, a recent study reported a significantly higher OS in patients with secondary myelofibrosis than with primary myelofibro- sis (26). A more recent study reported the opposite results, finding that the OS was significantly lower in patients with secondary myelofibrosis than in those with primary myelofibrosis (27). Taken together, these findings underscore the importance of analyzing the transplant outcome of secondary myelofibrosis in distinction from primary myelofibrosis.

In conclusion, it was confirmed that allogeneic HSCT provides a long-term survival for at least some patients with post-ET and post-PV myelofibrosis. Future studies with a large number of patients are needed to determine the best alternative donor, including UCB and HLA-haplo donor, the best preconditioning regimen for successful engraftment, and the best timing for allogeneic HSCT. 


\section{Author's disclosure of potential Conflicts of Interest (COI).} Ritsuro Suzuki: Advisory role, Gilead Sciences, Abbvie, Mundi Pharma, Jazz Pharma and Perseus Proteomics; Honoraria, Bristol-Myers Squibb, Novartis, Kyowa-Hakko Kirin, Chugai Pharmaceuticals, Shionogi, Takeda Pharmaceutical, Meiji Seika Pharma, MSD, Ohtsuka Pharmaceutical, Sawai Pharmaceutical, Celgene, Sumitomo Dainippon Pharma, Eisai, Alexion Pharma, Sanofi, Ono Pharmaceutical and Janssen Pharmaceuticals. Hitoshi Kiyoi: Honoraria, Bristol-Myers Squibb, Pfizer Japan and Astellas Pharma; Research funding, FUJIFILM, Kyowa Hakko Kirin, Bristol-Myers Squibb, Otsuka Pharmaceutical, Perseus Proteomics, Daiichi Sankyo, Zenyaku Kogyo, Nippon Shinyaku, Eisai, Chugai Pharmaceutical, Astellas Pharma, Takeda Pharmaceutical and Sumitomo Dainippon Pharma.

\section{Financial Support}

This study was supported in part by a Grant-in-Aid for Scientific Research (KAKENHI) (18K08321) from the Japan Society for the Promotion of Science (JSPS) to M. Murata and a Practical Research Project for Allergic Diseases and Immunology (19 ek0510022h0003) from the Japan Agency for Medical Research and Development (AMED) to M. Murata.

\section{Acknowledgement}

The authors would like to thank the staff at each transplant center and the staff at the Japanese Data Center for Hematopoietic Cell Transplantation.

\section{References}

1. Thiele J, Kvasnicka HM, Orazi A, et al. Essential thrombocythaemia. In: WHO Classification of Tumours of Haematopoietic and Lymphoid Tissues. Swerdlow SH, Campo E, Harris NL, et al., Eds. International Agency for Research on Cancer, Lyon, 2017: 50-53

2. Tefferi A, Guglielmelli P, Larson DR, et al. Long-term survival and blast transformation in molecularly annotated essential thrombocythemia, polycythemia vera, and myelofibrosis. Blood 124: 2507-2513, 2014.

3. Thiele J, Kvasnicka HM, Orazi A, Tefferi A, Birgegård G, Barbui T. Polycythaemia vera. In: WHO Classification of Tumours of Haematopoietic and Lymphoid Tissues. Swerdlow SH, Campo E, Harris NL, et al., Eds. International Agency for Research on Cancer, Lyon, 2017: 39-43.

4. Harrison C, Kiladjian JJ, Al-Ali HK, et al. JAK inhibition with ruxolitinib versus best available therapy for myelofibrosis. $\mathrm{N}$ Engl J Med 366: 787-798, 2012.

5. Kirito K, Okamoto S, Ohishi K, et al. Evaluation of the dose and efficacy of ruxolitinib in Japanese patients with myelofibrosis. Int J Hematol 107: 92-97, 2018.

6. Tefferi A. Myeloproliferative neoplasms: a decade of discoveries and treatment advances. Am J Hematol 91: 50-58, 2016.

7. Spivak JL. Myeloproliferative neoplasms. N Engl J Med 376: 2168-2181, 2017.

8. Kerbauy DM, Gooley TA, Sale GE, et al. Hematopoietic cell transplantation as curative therapy for idiopathic myelofibrosis, advanced polycythemia vera, and essential thrombocythemia. Biol Blood Marrow Transplant 13: 355-365, 2007.

9. Ballen KK, Woolfrey AE, Zhu X, et al. Allogeneic hematopoietic cell transplantation for advanced polycythemia vera and essential thrombocythemia. Biol Blood Marrow Transplant 18: 1446-1454, 2012.
10. Lussana F, Rambaldi A, Finazzi MC, et al. Allogeneic hematopoietic stem cell transplantation in patients with polycythemia vera or essential thrombocythemia transformed to myelofibrosis or acute myeloid leukemia: a report from the MPN Subcommittee of the Chronic Malignancies Working Party of the European Group for Blood and Marrow Transplantation. Haematologica 99: 916921, 2014.

11. Atsuta Y, Suzuki R, Yoshimi A, et al. Unification of hematopoietic stem cell transplantation registries in Japan and establishment of the TRUMP System. Int J Hematol 86: 269-274, 2007.

12. Atsuta Y. Introduction of Transplant Registry Unified Management Program 2 (TRUMP2): scripts for TRUMP data analyses, part I (variables other than HLA-related data). Int J Hematol 103: 3-10, 2016.

13. Giralt $\mathrm{S}$, Ballen $\mathrm{K}$, Rizzo D, et al. Reduced-intensity conditioning regimen workshop: defining the dose spectrum. Report of a workshop convened by the Center for International Blood and Marrow Transplant Research. Biol Blood Marrow Transplant 15: 367-369, 2009.

14. Przepiorka D, Weisdorf D, Martin P, et al. 1994 consensus conference on acute GVHD grading. Bone Marrow Transplant 15: 825828, 1995.

15. Shulman HM, Sullivan KM, Weiden PL, et al. Chronic graftversus-host syndrome in man. A long-term clinicopathologic study of 20 Seattle patients. Am J Med 69: 204-217, 1980.

16. Gooley TA, Leisenring W, Crowley J, Storer BE. Estimation of failure probabilities in the presence of competing risks: new representations of old estimators. Stat Med 18: 695-706, 1999.

17. Kaplan EL, Meier P. Nonparametric estimation from incomplete observations. J Am Stat Assoc 53: 457-481, 1958.

18. Cox DR. Regression models and life tables. J Royal Stat Soc [B] 34: 187-220, 1972.

19. Robin M, Giannotti F, Deconinck E, et al. Unrelated cord blood transplantation for patients with primary or secondary myelofibrosis. Biol Blood Marrow Transplant 20: 1841-1846, 2014.

20. Takagi S, Ota Y, Uchida N, et al. Successful engraftment after reduced-intensity umbilical cord blood transplantation for myelofibrosis. Blood 116: 649-652, 2010.

21. Murata M, Takenaka K, Uchida N, et al. Comparison of outcomes of allogeneic transplantation for primary myelofibrosis among hematopoietic stem cell source groups. Biol Blood Marrow Transplant 25: 1536-1543, 2019.

22. Bacigalupo A, Soraru M, Dominietto A, et al. Allogeneic hemopoietic SCT for patients with primary myelofibrosis: a predictive transplant score based on transfusion requirement, spleen size and donor type. Bone Marrow Transplant 45: 458-463, 2010.

23. Murata M, Nishida T, Taniguchi $S$, et al. Allogeneic transplantation for primary myelofibrosis with BM, peripheral blood or umbilical cord blood: an analysis of the JSHCT. Bone Marrow Transplant 49: 355-360, 2014.

24. Gangat N, Caramazza D, Vaidya R, et al. DIPSS plus: a refined Dynamic International Prognostic Scoring System for primary myelofibrosis that incorporates prognostic information from karyotype, platelet count, and transfusion status. J Clin Oncol 29: 392397, 2011.

25. Takenaka K, Shimoda K, Uchida N, et al. Clinical features and outcomes of patients with primary myelofibrosis in Japan: report of a 17-year nationwide survey by the Idiopathic Disorders of Hematopoietic Organs Research Committee of Japan. Int J Hematol 105: 59-69, 2017.

26. Samuelson Bannow BT, Salit RB, Storer BE, et al. Hematopoietic cell transplantation for myelofibrosis: The Dynamic International Prognostic Scoring System Plus risk predicts post-transplant outcomes. Biol Blood Marrow Transplant 24: 386-392, 2018.

27. Robin M, de Wreede LC, Wolschke C, et al. Long-term outcome after allogeneic hematopoietic cell transplantation for myelofibro- 
sis. Haematologica 104: 1782-1788, 2019.

28. Patriarca F, Bacigalupo A, Sperotto A, et al. Allogeneic hematopoietic stem cell transplantation in myelofibrosis: the 20-year experience of the Gruppo Italiano Trapianto di Midollo Osseo (GITMO). Haematologica 93: 1514-1522, 2008.

29. Shanavas M, Popat U, Michaelis LC, et al. Outcomes of allogeneic hematopoietic cell transplantation in patients with myelofibrosis with prior exposure to Janus kinase 1/2 inhibitors. Biol Blood Marrow Transplant 22: 432-440, 2016.

30. Shahnaz Syed Abd Kadir S, Christopeit M, Wulf G, et al. Impact of ruxolitinib pretreatment on outcomes after allogeneic stem cell transplantation in patients with myelofibrosis. Eur J Haematol 101:
305-317, 2018.

31. Raj K, Eikema DJ, McLornan DP, et al. Family mismatched allogeneic stem cell transplantation for myelofibrosis: report from the Chronic Malignancies Working Party of European Society for Blood and Marrow Transplantation. Biol Blood Marrow Transplant 25: 522-528, 2019.

The Internal Medicine is an Open Access journal distributed under the Creative Commons Attribution-NonCommercial-NoDerivatives 4.0 International License. To view the details of this license, please visit (https://creativecommons.org/licenses/ by-nc-nd/4.0/).

(C) 2020 The Japanese Society of Internal Medicine Intern Med 59: 1947-1956, 2020 